\title{
Follow-up study of the treatment outcomes at a psychiatric trauma clinic for refugees
}

\author{
Cæcilie Buhmann, MD, PhD*, Erik Lykke Mortensen, MSc**, Merete Nordentoft, \\ DrMSc***, Jasmina Ryberg, MD*, Morten Ekstrøm, MD, PhD*
}

\begin{abstract}
Purpose: To describe change in mental health after treatment with antidepressants and trauma-focused cognitive behavioral therapy.
\end{abstract}

Methods: Patients receiving treatment at the Psychiatric Trauma Clinic for Refugees in Copenhagen completed self-ratings of level of functioning, quality of life, and symptoms of PTSD, depression and anxiety before and after treatment. Changes in mental state and predictors of change were evaluated in a sample that all received well-described and comparable treatment.

Results: 85 patients with PTSD or depression were included in the analysis. Significant improvement and effect size were observed on all rating scales ( $\mathrm{p}$-value $<0.01$ and Cohen's d 45-0.68). Correlation analysis showed no association between severity of symptoms at baseline and the observed change.

Conclusion: Despite methodological limitations, the finding of a significant improvement on all rating scales is important considering that previous follow-up studies

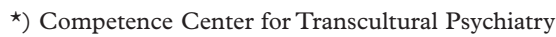
(CTP), Psychiatric Center Ballerup, the Mental Health Services of the Capital Region of Denmark

$\star \star)$ Institute for Public Health, University of Copenhagen

$\star \star \star)$ Psychiatric Center Copenhagen, the Mental Health Services of the Capital Region of Denmark
}

Correspondence to: caecilie.boeck.buhmann@regionh.dk of comparable patient populations have not found significant change in the patients' condition after treatment.

Keywords: refugee, trauma, CBT, antidepressants, PTSD, treatment outcome

\section{Introduction}

Despite the size of the problem, there is very limited knowledge about the efficiency of psychiatric treatments for trauma-exposed refugees. Typically, the target group suffers from post-traumatic stress disorder (PTSD), anxiety and depression. According to the most recent Cochrane Review, TraumaFocused Cognitive Behavioural Therapy (TFCBT) is the best documented psychotherapeutic treatment for PTSD while pharmacological treatment with antidepressants (Selective Serotonergic Reuptake Inhibitor (SSRI)) has also proved effective, ${ }^{1,2}$ but it has yet to be documented whether a combination of the two is more effective than using either psychotherapy or pharmacological treatment. ${ }^{3}$ The available results are mostly based on studies of other patient populations than traumatized refugees, such as American war veterans or victims of traffic accidents. Whether this knowledge can be transferred to severely traumatized refugees is unclear. Refugees often have several co-morbidities, have suffered many consecutive traumas that often continue after arrival in their new country of residence, are subject 
to numerous psychosocial stressors such as insecure legal status and limited income and social networks, and their mental health problems are often chronic in nature. In addition, it is yet to be fully understood how the transcultural characteristics of traumatized refugees affect the outcome of treatments. Specific trials on refugees are therefore needed.

A systematic review from $2010^{4}$ specifically evaluated trials on refugee populations, but only 10 trials had comparable populations and used an acceptable methodology. Even these studies differed with regards to ethnic groups, legal status of the patients, co-morbidities and outcome measures. Several studies of multi-disciplinary treatment for refugee populations in Denmark have been published, but they were based on small samples receiving ill-defined treatment and detected no significant change in the condition of the patients. ${ }^{5-9}$ Thus, knowledge of how to address the psychosocial problems of traumatized refugees is limited albeit of most importance. ${ }^{10}$ The aim of the present study is to evaluate the change in the condition of the patients after a combination treatment with flexible Cognitive Behavioral Therapy (CBT) and antidepressants at a trauma clinic for refugees in Copenhagen.

\section{Participants and Design}

The study is a follow-up study with patients answering self-ratings before, during and after treatment. All participants were screened at the Psychiatric Trauma Clinic for Refugees in Copenhagen during the period April 2008 to June 2009. The included patients were 18 years or older. They had experienced trauma related to war or persecution, including torture, and suffered from disorders such as depression and PTSD, which are known to occur after traumas. The patients had received a minimum treatment of four months' duration including treatment with an antidepressant, had received at least four consultations with a therapist, and had at least two outcome ratings (out of four possible) from baseline assessment and follow-up. Diagnoses were made according to ICD-10 research criteria and all individual symptoms were recorded. Patients were excluded if diagnosed with a psychosis, bipolar disorder (F22-29 of F31) or any substance abuse apart from the regular use of benzodiazepines according to ICD-10. Patients who were in need of hospitalization in the general psychiatric system were not enrolled in treatment at the clinic. The study was conducted in accordance with the Helsinki Declaration and was approved by the Danish National Committee on Biomedical Research Ethics as well as by the Danish Data Protection Agency.

\section{Data collection}

Data collected during the initial assessment (two hours with a physician and one hour with a social worker) included self-ratings, a clinical assessment of the current psychiatric status and a structured interview collecting information on trauma, socioeconomic situation, previous mental health problems and treatment, current physical health problems and diagnosis according to the ICD-10 research criteria. At every consultation, treatment methods were recorded and the patient's current clinical condition was rated by the health professional responsible for the consultation. In addition to the self-ratings completed at baseline assessment, the same self-report instruments were answered before CBT treatment was initiated (usually after six weeks) and by the end of the treatment. Physicians with transcultural psychiatric experience with trauma exposed patients were responsible for 
the assessment and diagnosis of participants. If necessary, translation was provided during assessment and treatment consultations. All self-report questionnaires were translated into the six most common languages at the clinic (Arabic, Farsi, Bosnian / Serbo-Croatian, Russian, Danish and English), which included the language of $86 \%$ of the patients.

The self-ratings included PTSD symptoms (Harvard Trauma Questionnaire), depression and anxiety symptoms (Hopkins Symptom Checklist-25), quality of life (WHO-5) and the level of functioning (Sheehan Disability Scale). The Hopkins Symptom Check List-25 (HSCL-25) and the Harvard Trauma Questionnaire (HTQ) are internationally used and validated self-report rating scales. ${ }^{11-14}$ HSCL-25 is a shorter version of the Symptom Checklist-90 with a focus on anxiety and depression symptoms. HTQ is used to evaluate PTSD. We used the first 16 questions of the symptom part (Part IV) of HTQ, which are used to evaluate the PTSD-diagnosis according to ICD-10 and DSM-IV. Both HSCL-25 and HTQ have mainly been used on refugees and torture victims. For both scales, individual questions have a 1-4 Likert format with 4 the highest symptom level. The cut-off value for case status of HTQ is 2.5 and of HSCL-25 1.75. To assess quality of life we used the WHO- 5 scale, which is a widely used self-administered questionnaire with 5 questions (0-5 point Likert scale with 0 being the lowest score and 5 the highest). The theoretical raw score ranges from 0 to 25 and is transformed into a scale from 0 (worst thinkable wellbeing) to 100 (best thinkable well-being) by multiplying the score by 4 . Thus, higher scores mean better well-being. ${ }^{15}$ The Sheehan Disability Scale (SDS) is a selfreport rating scale which assesses the level of functioning in terms of family, work and social network by using 3 visual analogue scales from $0-10$ with 10 being the lowest possible level of functioning. The score is usually reported as the total score of the three scales ranging from $0-30$. Cut-off is considered to be 15 if the total score is reported. The scale has been used in a variety of psychiatric patient groups. ${ }^{16-17}$

\section{Statistical analysis}

The change in self-rating scores between the beginning and the end of the treatment was evaluated with a paired t-test. An improvement on the HSCL-25, HTQ and SDS scales means a decline in the value while an improvement on the WHO-5 represents an increase in scores. In addition to this, Cohen's d was calculated (mean change divided by the standard deviation at baseline $)^{18}$ to evaluate the effect size of change on each self-rating scale and Pearson correlations were used to calculate the correlation between outcome measures and correlation between baseline and follow-up. Finally, a measure of reliable change was calculated ${ }^{19}$ for each outcome rating scale. The Reliable Change Index (RCI) is a measure of the minimum individual change in pre-to post-treatment ratings, which is statistically significant. ${ }^{20}$ In addition to descriptive statistics, linear univariate and multivariate regression models were used to investigate possible associations between change in the patient's state and potential predictors of change. Change was measured as the difference between ratings at baseline and at follow-up, and all regression models were adjusted for baseline scores. The predictors included in the univariate analyses of each outcome variable were those mentioned in Table 1 and 2 in addition to the following predictors related to their trauma and mental health history: Being an ex-combatant, having been persecuted, having lived in a refugee camp, been in prison, been politically 
active in country of origin, lived in asylum camp in Denmark, number of different types of pre-migratory traumas and not having mental health problems.

Table 1: Overview of the mental health at baseline, socioeconomic vulnerabilities and the components of the treatment received amongst traumatized refugees at a clinic in Copenhagen $(N=85)$

\begin{tabular}{lll}
\hline Background & $\%$ & N
\end{tabular}

\section{Health at baseline}

PTSD

Depression (moderate or severe)

Reports pain

Assessed psychotic during treatment

Treated physical symptoms at assessment Untreated physical symptoms at assessment (excluding pain and headache)

Previous psychopharmacological treatment Previous treatment including psychotherapy Any education

Working at the time of assessment

Permanent Resident status

Trauma

Experienced war

Been subjected to torture
87

98

99

15

49

94

80

88

76

10

90

86

54

46

Sex

Male

Main Ethnic Groups

$\begin{array}{rlr}\text { Iraqi } & 36 & 31 \\ \text { Iranian } & 11 & 9 \\ \text { Lebanese /Palestinian } & 15 & 13 \\ \text { Others } & 38 & 32 \\ & 49 & 42\end{array}$




\begin{tabular}{lrr}
\hline & Mean (min-max) & $\begin{array}{r}\text { Standard } \\
\text { deviation }\end{array}$ \\
\hline Mean number of years in Denmark & $14.5(2-30)$ & 6.4 \\
Age & $43.4(21-57)$ & 8.0 \\
Mean number of years since first trauma & $22.6(4-46)$ & 8.9
\end{tabular}

Treatment

Medicines

$\begin{array}{rrr}\text { Sertraline } & 24 & 20 \\ \text { Mianserin } & 4 & 3 \\ \text { Sertraline \& Mianserin } & 73 & 62 \\ \text { Antipsychotics } & 9 & 8 \\ \text { Benzodiazepines } & 9 & 8 \\ \text { armacological medicines } & 13 & 11 \\ \text { during treatment } & & \end{array}$

Received psychoeducation as part of treat-

99

84

ment

Mean (min-max) s

Psychoeducation topics covered

$5.7(0-10) \quad 2.3$

Session with physician

$8.7(4-14) \quad 1.7$

Total duration of treatment (months)

$8.2(5.4-13.1) \quad 1.5$

Total number of sessions

$22.3(11-38) \quad 4.2$

Sessions with psychologist

$13.5(4-24) \quad 3.4$

Duration of Psychotherapy (months)

$5.6(3-10)$

1.2 
Table 2: Change in outcome measured by Hopkin's Symptom Checklist-25 (depression \& anxiety), Harvard Trauma Questionnaire (PTSD), Sheehan Disability Scale (level of functioning) and WHO-5 (quality of life)

\begin{tabular}{|c|c|c|c|c|c|c|c|}
\hline Rating & $\mathbf{N}$ & $\begin{array}{l}\text { Mean_- } \\
\text { baseline } \\
\text { (SD) }\end{array}$ & $\begin{array}{l}\text { Mean_- } \\
\text { follow-up } \\
\text { (SD) }\end{array}$ & $\begin{array}{l}\text { Mean_ } \\
\operatorname{diff}(S D)\end{array}$ & CI-95\% & $\begin{array}{l}\text { Cohens d } \\
\text { (Mean } \\
\text { diff / SD } \\
\text { baeline) }\end{array}$ & $\begin{array}{l}\text { P-value } \\
\text { (t-test) }\end{array}$ \\
\hline WHO-5 & 80 & $\begin{array}{l}14.76 \\
(15.74)\end{array}$ & $\begin{array}{l}24.28 \\
(23.61)\end{array}$ & $\begin{array}{l}9.50 \\
(21.35)\end{array}$ & $\begin{array}{l}4.75- \\
14.25\end{array}$ & 0.60 & $<0.01$ \\
\hline SDS & 81 & $\begin{array}{l}23.92 \\
(4.27)\end{array}$ & $\begin{array}{l}21.56 \\
(6.80)\end{array}$ & $\begin{array}{l}2.36 \\
(5.67)\end{array}$ & $\begin{array}{l}1.11 \\
-3.62\end{array}$ & 0.55 & $<0.01$ \\
\hline HTQ & 80 & $\begin{array}{l}3.26 \\
(0.42)\end{array}$ & $\begin{array}{l}2.96 \\
(0.55)\end{array}$ & $\begin{array}{l}0.30 \\
(0.44)\end{array}$ & $0.20-0.40$ & 0.68 & $<0.01$ \\
\hline HSCL-25 & 75 & $\begin{array}{l}3.21 \\
(0.44)\end{array}$ & $\begin{array}{l}2.95 \\
(0.63)\end{array}$ & $\begin{array}{l}0.26 \\
(0.56)\end{array}$ & $0.13-0.39$ & 0.59 & $<0.01$ \\
\hline $\begin{array}{l}\text { HSCL- } \\
\text { depres- } \\
\text { sion }\end{array}$ & 77 & $\begin{array}{l}3.21 \\
(0.46)\end{array}$ & $\begin{array}{l}2.94 \\
(0.64)\end{array}$ & $\begin{array}{l}0.27 \\
(0.56)\end{array}$ & $0.14-0.40$ & 0.59 & $<0.01$ \\
\hline $\begin{array}{l}\text { HSCL- } \\
\text { anxiety }\end{array}$ & 82 & $\begin{array}{l}3.20 \\
(0.55)\end{array}$ & $\begin{array}{l}2.95 \\
(0.68)\end{array}$ & $\begin{array}{l}0.25 \\
(0.61)\end{array}$ & $0.11-0.38$ & 0.45 & $<0.01$ \\
\hline
\end{tabular}

In addition to this, the following predictors related to current health and socioeconomic condition were included: social isolation, income, number of locations with pain, pain in arms, pain in legs, pain in back and headache. Variables, which in univariate regression models were found to be significantly associated with change in the patient's state $(\mathrm{p} \leq 0.05)$, were all included in multivariate regression models. HTQ and HSCL-25 multivariate models included the following predictors: employment, pain in the arms, use of a translator, patient suitability score, use of case formulation, use of thought records, use of values mean number of therapy methods used, homework compliance and the total number of sessions with a psychologist. The psychotherapy-related variables are described in detail in a separate article. ${ }^{20}$ All statistical analyses were made in STATA 11 (StataCorp LP, College Station, TX, USA). 


\section{The intervention}

The treatment at the clinic was standardized and described in manuals which all physicians and clinical psychologists followed to the extent possible (see Figure 1).

Figure 1: Standard treatment flow and ratings

\begin{tabular}{|c|c|}
\hline Week 1-2 & $\begin{array}{c}\text { Baseline assessment } \\
\text { by physician }\end{array}$ \\
\hline Week 3-8 & $\begin{array}{c}\text { Weekly adjustment of } \\
\text { pharmaco-therapy and } \\
\text { psychoeducation by } \\
\text { physician }\end{array}$ \\
\hline Week 9-24 & $\begin{array}{c}\text { Monthly adjustment of } \\
\text { pharmaco-therapy and } \\
\text { psychoeducation by } \\
\text { physician }\end{array}$ \\
\hline
\end{tabular}

tations included psychoeducation about the illness, the treatment, life in exile, the role of religion, sleep, life-style including relaxationexercises, physical and social activities, pain, cognitive functions, and the influence of the 1st rating by social worker

\author{
Weekly CBT therapy \\ session (45 min) with \\ psychologist
}

3rd rating

A standard period of six months included 10 consultations with a doctor experienced in transcultural psychiatry who is responsible for the medical treatment of the patient. The doses of Sertraline and Mianserin and change in medication followed the recommendations of The Danish Medicines Agency and the Maudsley Prescription Guidelines. The first choice medication was Sertraline. It was increased by $25 \mathrm{mg}$ per week to a maximum dose of 200 mgs. Sertraline could be supplemented with 10-30 mgs of Mianserin if the patients had trouble sleeping. Whenever possible, any other psychopharmacological treatment was reduced or stopped. In addition, the consul- illness on the family. Parallel to the psychopharmacological treatment and psychoeducation, the patients received CBT during 16 consultations with a clinical psychologist. All psychologists had received training in CBT and treatment of trauma survivors and were regularly supervised by CBT experts. The psychotherapy and medical sessions were planned to be weekly, but patients from the study population did not regularly show up for appointments, which tended to increase the interval between consultations and the overall treatment period as well as to reduce the average number of consultations during a treatment course (See Figure 1).

The fidelity with the treatment manual 
depended on the patient's ability to cooperate in therapy. Therefore, the inclusion criteria for this study were slightly more flexible than the standardized treatment requirements.

The patients saw a social worker at least once during the treatment period.

\section{Results}

During the study period, 166 patients were screened at the clinic. Of these, 21 were excluded because of psychosis or drug abuse while 17 were not included because they did not have a trauma-related diagnosis such as PTSD or depression according to ICD-10. We excluded 29 patients from analysis because they had not received a full treatment course. Finally, 14 patients were excluded due to incomplete data (did not have 1 st and 3rd rating). Thus, the presented analyses are based on a study sample consisting of 85 patients, which means that $43(34 \%)$ patients were excluded from the final sample because of drop-out of treatment or incomplete data. The non-completers did not differ markedly from the completers at baseline. Of all ratings, only HSCL-25 differed significantly, with a mean score for completers of 3.2 and of non-completers of $3.0(p=0.05)$, suggesting marginally less depression and anxiety symptom intensity in non-completers compared with completers.

\section{Patients' background}

The majority (77\%) of patients came from the Middle East. Iraqi patients alone comprised $36 \%$ of the study population. Men and women were almost equally represented and the average age was 43 years at baseline assessment. The majority of patients $(86 \%)$ had experienced war in their country of origin and $54 \%$ had been subjected to torture. Table 1 shows that patients overall had very limited psychosocial resources and suffered from several health problems. Most of the patients were married and had children, but $34 \%$ of patients had no contact with friends or family in Denmark. Among the patients, $90 \%$ had permanent resident status in Denmark, but only eight patients were employed at baseline assessment and half of the patients needed translation during treatment despite a mean of 14 years spent in Denmark. The average time since first trauma was 23 years indicating chronic late effects. Of the study sample, $99 \%$ of patients complained of pain, $49 \%$ of patients had medically treated physical symptoms, 94\% had unexplained physical symptoms and $15 \%$ described current or previous psychotic symptoms at baseline assessment. Patients had either depression or PTSD and $85 \%$ of patients had both during assessment (see Table 1).

\section{Treatment received}

The average treatment-time was eight months including on average nine sessions with a doctor and 14 psychotherapy sessions. All but one patient received psychoeducation and an average of 6 out of 10 possible topics were covered. All the patients received manualized CBT including exposure, mindfulness and acceptance and commitment therapy methods and an average of 12 of the $21 \mathrm{CBT}$ methods included in the manual were used with each patient. The majority of patients $(72 \%)$ were treated with a combination of Mianserin (average dose $15 \mathrm{mg}$ ) and the SSRI Sertraline (average dose $125 \mathrm{mg}$ ). The rest of the patients received treatment with only one of the antidepressants. Of the patients, 11 were also treated with antipsychotics and/or benzodiazepines after the largest possible reduction in psychopharmacological treatment at baseline. At baseline 28 patients were treated with more than one type of 
psychopharmacological drug and 22 patients stopped taking benzodiazepines during treatment (see Table 1).

\section{Change in condition}

\section{Ratings}

At baseline assessment most patients had high scores on the self-report rating scales: On HTQ the patients had a mean score of 3.25. On HSCL-25 the mean score was 3.21. On SDS the baseline mean score was 8 (10 being the lowest possible level of functioning) and the mean WHO-5 score was 15 (with 100 being the best possible quality of life). Positive changes were seen on all rating scales (see Table 2), and they were unlikely to be due to chance ( $p$-values $<0.0004)$. The individual items on the rating scales which showed the largest statistical change during treatment were sleep (on WHO-5, HTQ and HSCL-25), irritation (HTQ), hopelessness (HTQ and HSCL-25), feeling blue, low in energy, restlessness and nervousness (HSCL-25). There was some improvement in level of functioning with regard to work and social life. The symptoms that changed the least were physical symptoms associated with anxiety and depression (like poor appetite, trembling and heart pounding), shame and feeling of worthlessness and fear (avoidance, fearfulness and being on guard). The overall changes on the scales had a mean Cohen's d at about 0.6 (ranging from 0.44 on the HSCL-25 anxiety scale to 0.67 on HTQ), and thus moderate effects of the treatment were observed by Cohen's standards at the group level (19). On HTQ $30 \%$ of patients showed reliable change from baseline to follow-up, whereas the proportion of patients with a statistically significant individual change for the other rating scales was 35\% for HSCL-25 28\% for WHO-5 and $16 \%$ for SDS (see Table 2 \& Figures 2 to 4 for change in condition).

\section{Predictors of change}

Few parameters seemed to predict change in the patient's condition during treatment. In multivariate regression models improvement

Figure 2: Change in level of functioning

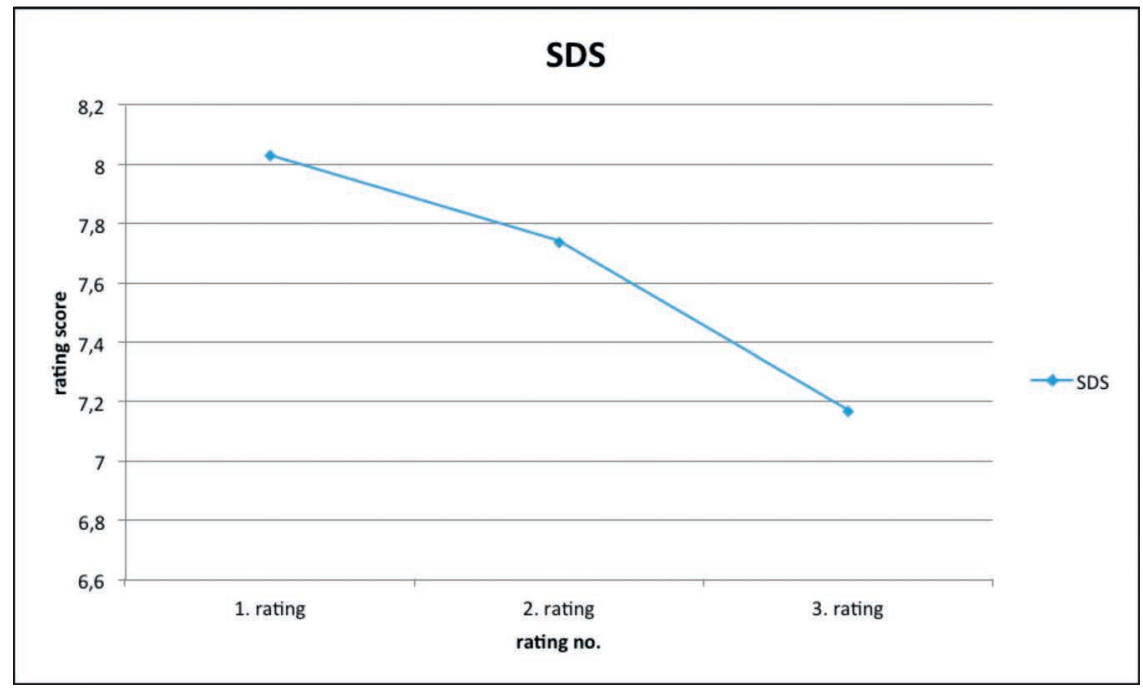


Figure 3: Change in symptoms

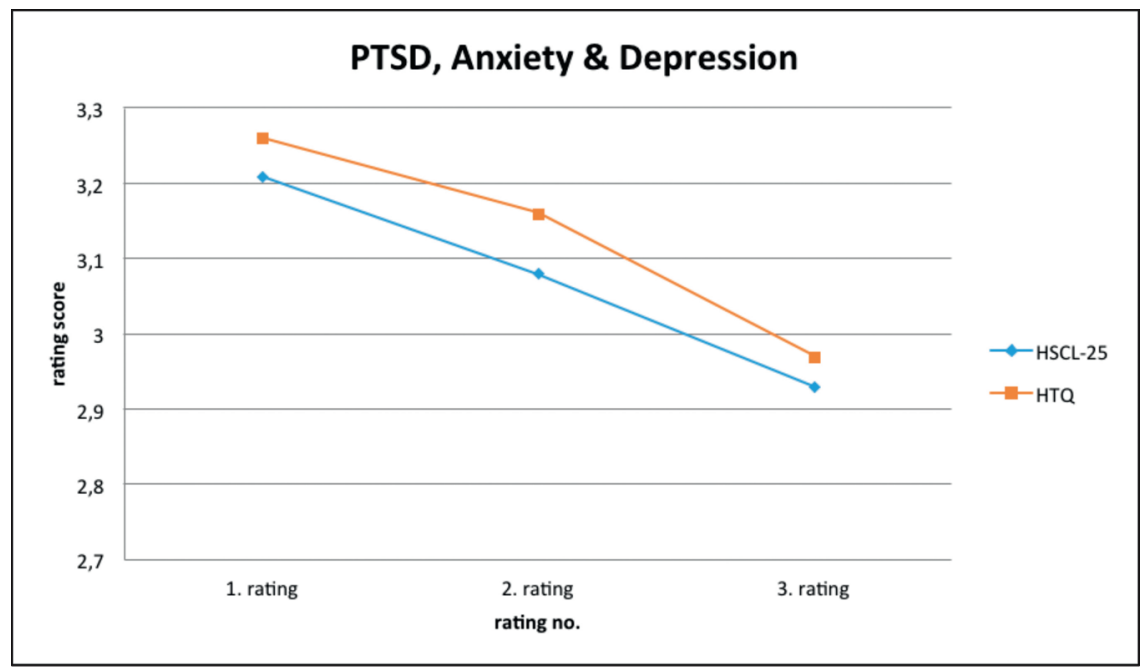

Figure 4: Change in quality of life

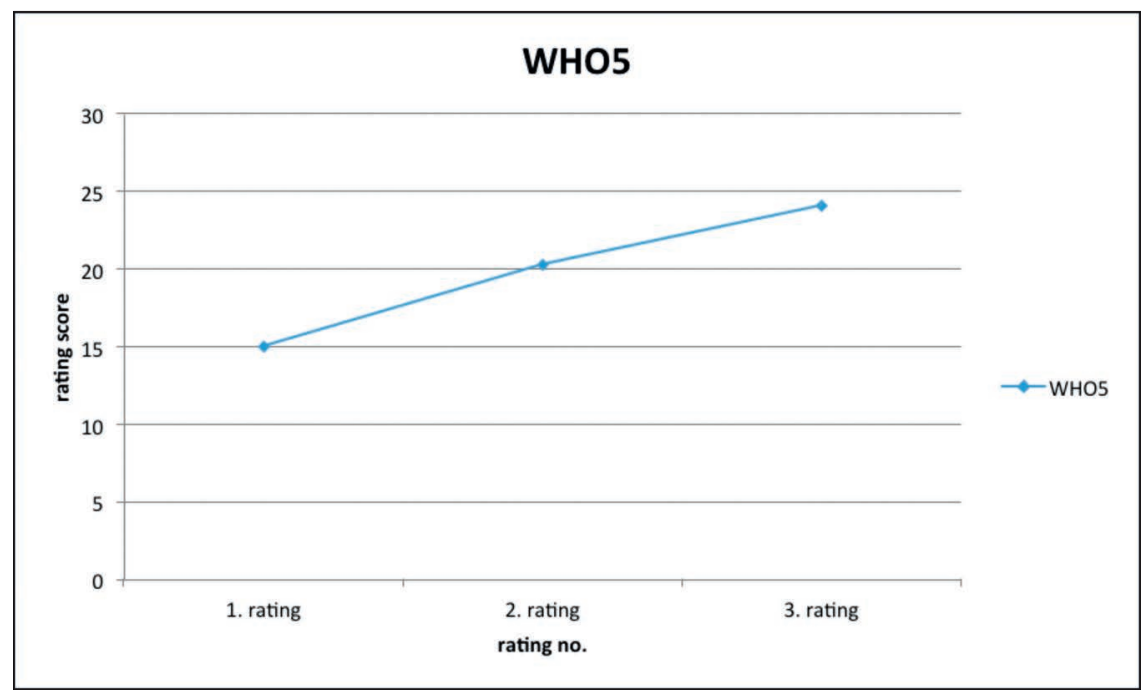


in HTQ score was negatively associated with being on public financial support $(B=0.42$, $\mathrm{p}=0.01, \mathrm{CI}=0.11-0.74)$. In addition to this, improvement in HSCL-25 scores was negatively associated with pain in the arms $(\beta=0.37, p=0.03, C I=0.05-0.68))$ in multivariate regression. Improvement in SDS and WHO-5 scores was not significantly associated with any of the potential predictors in multivariate regression analysis. We have examined a possible correlation between the baseline values and the changes in the mental condition by calculating the correlation coefficients. They were very close to zero for all 4 scales ranging from 0.1 on SDS to 0.2 on HSCL-25 and WHO-5.

\section{Discussion}

We found significant improvement in the patients' symptoms of PTSD (HTQ), depression and anxiety (HSCL-25), quality of life (WHO-5) and level of functioning (SDS), but this study obviously cannot rule out the possibility that the observed changes over the six-month treatment period primarily reflect spontaneous recovery and not effects of the administered treatment. This must be further investigated in studies with control groups and optimally randomized trials. However, the patients reported the original trauma to date back more than 20 years $(95 \%$ of patients reported trauma to be more than 10 years old), and this suggests that the observed changes in rating scale scores are unlikely to reflect spontaneous changes in the condition of the patients. A previous study of a similar patient population in Denmark found no significant change in clinical condition of patients ${ }^{5}$ and this finding corroborates the assumption that our findings reflect regression towards the mean. However, it is possible that patients seek treatment when their condition is at its worst and that the improvement observed is therefore due to a natural fluctuation in their condition. The observed changes did not move the majority of patients beyond the cut-off scores on the rating scales, suggesting that the majority had clinically significant symptoms of depression and PTSD after the treatment. However, it would require a treatment with a very large effect to move the majority of patients below cut-off given the very high baseline scores observed on all rating scales.

It has been suggested that standard rating scales for symptoms (HTQ and HSCL-25) in this patient group are less well-suited to measure treatment outcomes. ${ }^{21}$ For instance, a Danish study on a comparable group of patients found no changes in symptoms, but only changes in level of functioning and quality of life at an initial follow-up while only changes in symptoms were identified at a long-term follow-up..$^{5-7}$ The present study cannot confirm these findings as we see similar changes on all rating scales. In addition to this, a recent study of the validity of HTQ and HSCL-25 in different cultural groups has questioned the use of standard cut-off values of 2.5 for HTQ and 1.75 for HSCL-25, which will influence estimates of the number of patients below cut-off. ${ }^{22}$ Finally, traumatized refugees suffer from many different mental and physical problems, not only PTSD and depression, ${ }^{23}$ and their trauma-related symptoms have often been present for very long periods of time. This was not measured with the rating scales used in the study.

The strength of the study is the detailed description of the patients at baseline, and of the treatment they received. ${ }^{20,23}$ This study is one of the first to evaluate a standardized treatment described in detail in manuals and documented thoroughly during treatment. This has enabled us to ensure that the group actually receives the same intervention, 
which has been one of the many methodological problems of other studies on refugee populations using multi-disciplinary treatment. ${ }^{5,6,8}$ The lack of well-described treatments may reflect variability in the administered treatments or reflect a situation where an otherwise standardized treatment has not been described in sufficient detail to be replicated. This is an important problem when comparing treatment outcomes. The statistically significant change observed in this study may be the result of an efficient and standardized intervention that was administered to patients in the study sample.

A correlation has been found in many studies between the scores at the beginning of the treatment and the changes seen in the course of the treatment. This was not the case in the present study. The symptoms which improved most during treatment were sleep, general symptoms of depression and general feelings of anxiety. Overall changes in rating scores were largest on HTQ. The CBT had been designed to address PTSD specifically and this might be a reason for the significant improvements in PTSD. The effects of Sertraline are not only to decrease symptoms of depression, but also to decrease generalized anxiety ${ }^{24}$ which might explain the changes on these parameters. Finally, the overall biggest change in symptoms was with regard to sleep (improvement with a large statistical effect on all scales measuring sleep). This could reflect the use of Mianserin, which is known for its positive effect on sleep disturbances, ${ }^{25}$ although we did not find a correlation between change in sleep items on HSCL-25 and HTQ and Mianserin. However, to confirm this a study where the individual treatment components were evaluated separately would be necessary. For the benefit of future treatment development, it would be very important to evaluate the effect of the different treatment components separately and compare them to combination treatment to rule out the possibility that each of the components alone would have the same effect as the more costly combination. This is in accordance with the conclusions of a recently published Cochrane Review of combination treatment. ${ }^{3}$

We found few predictors of treatment outcome, but several factors can explain these results. The sample size was small and we would only be able to detect substantial effects of predictors, which may be unlikely. The sample was very homogeneous with respect to some of the predictors of treatment outcome whereas the distribution of others was more heterogeneous. Study sample selection means that the treatment was similar with regard to duration, number of consultations, psychopharmacological treatment, psychoeducation and psychotherapy. Almost all patients suffered from the same problems at baseline including pain, somatic complaints and several trauma-related diseases, and all patients with psychosis, bipolar disorder or substance abuse were excluded. Furthermore, the patients were also homogeneous with respect to socioeconomic factors such as income, legal status, and employment (see Table 1). It has been suggested that current psychosocial stressors may substantially influence treatment outcomes in studies of traumatized refugees ${ }^{10}$ but the literature on the association between psychosocial factors and treatment outcome is inconclusive. ${ }^{23,26,27}$ There is some evidence that income and economic strain influence the condition of traumatized refugees. ${ }^{26,28-31}$ One other Danish study has found an association between pain in the arms and patient condition in a similar sample of refugees. ${ }^{32}$ There is also evidence that post-migratory stressors play an increasingly important role in relation to mental health the longer refugees have been 
in the receiving country. ${ }^{6,33,34}$ This could explain why we did not find any clear association between pre-migratory predictors such as type of trauma and change in the patients' condition.

We found that improvement in depression and anxiety on HSCL-25 was associated with pain in the arms and that being on public financial support was negatively associated with PTSD improvement. Although other pain variables were included in the regression analysis only pain in the arms was significantly associated with treatment outcome in multivariate analysis. This could be due to larger variation in pain in the arms than the other pain variables. However, another study has also found pain in the arms to predict patient condition in a similar patient sample. ${ }^{32}$ We found that more torture survivors had pain (66\%) than those who had not endured torture $(33 \%)$, which might partially explain the finding. Chronic pain, PTSD and depression has also been shown to be related in other studies although it remains unclear whether depression is the main factor associated with chronic pain or if PTSD and anxiety disorders are independently related to chronic pain. ${ }^{35-37}$

It is not surprising that improvement in PTSD is associated with socioeconomic conditions. Families living on social welfare are living in relative poverty in Denmark and have to participate in job training and language classes, which is a stressor for many patients. The finding that reports of previous psychotic symptoms or treatment for psychotic symptoms were positively associated with an improvement in level of functioning is interesting. It is possible that these patients in previous treatments only had received treatment for psychotic disorder and not their trauma-related disease. ${ }^{38}$ If the psychotic symptoms are an integral part of the trauma-related mental distress they could be expected to improve together with other trauma-related symptoms. This finding must be investigated further in future studies.

So far, the best results of treatments evaluated with randomized trials ${ }^{4}$ were found in populations displaced within their original region who received Narrative Exposure Therapy ${ }^{39-41}$ and in a highly selected Southeast Asian patient population treated in Boston. ${ }^{42-44}$ It is therefore an important finding that our CBT and psychopharmacological treatment seems to be associated with a positive change in the patient condition from baseline to follow-up. However, the association between treatment and improvement needs to be confirmed in studies including a control group and blinded ratings including observer-ratings to complement the subjective evaluations made by patients.

\section{Conclusion}

The study showed statistically significant changes in the condition of the patients from assessment before treatment to follow-up. Few other studies have found similar results and the observed changes may depend on the target patient population. Our population is similar to those described in other Scandinavian studies ${ }^{5,6,8,45}$ which found little or no change in patient condition after treatment. More studies with improved methodology using well-described treatment on well-characterized patients are necessary, and we have now demonstrated that it is possible to conduct such studies. Presumably, a more effective treatment of traumatized refugees requires a better classification of patient diagnoses reflecting not only PTSD, but also co-morbid symptom complexes, as well as psychotherapeutic and pharmacological treatment directed at all the problems of the patient, including somatic complaints, pain and psychotic symptoms. If 
our results can be confirmed in future studies with better methodology, they might indicate that evidence from research in other patient populations may be transferable to the refugee context. On the other hand, the patient population suffers from many other problems than PTSD, and consequently there are reasons to include other elements in the treatment to further improve the outcome.

\section{Acknowledgements}

We would like to thank all the employees at the Psychiatric Trauma Clinic for Refugees who have contributed to collection and management of data in the study.

The article and research project is part of the work for a $\mathrm{PhD}$ thesis. The project is funded by the Capital Region Psychiatry, Denmark, which is a public healthcare institution. 


\section{References}

1. Bisson J, Andrew M. Psychological treatment of post-traumatic stress disorder (PTSD). Cochrane Database Syst Rev. 2007 Jul 18;(3).

2. Stein DJ, Ipser JC, Seedat S. Pharmacotherapy for post traumatic stress disorder (PTSD). Cochrane Database Syst Rev. 2006 Jan 25;(1).

3. Hetrick SE, Purcell R, Garner B, Parslow R. Combined pharmacotherapy and psychological therapies for post traumatic stress disorder (PTSD). Cochrane Database Syst Rev. 2010 Jul $7 ;(7)$.

4. Crumlish N, O'Rourke K. A systematic review of treatments for post-traumatic stress disorder among refugees and asylum-seekers. J Nerv Ment Dis. 2010 Apr;198(4):237-51.

5. Carlsson JM, Mortensen EL, Kastrup M. A follow-up study of mental health and healthrelated quality of life in tortured refugees in multidisciplinary treatment. J Nerv Ment Dis. 2005 Oct;193(10):651-7.

6. Carlsson JM, Olsen DR, Mortensen EL, Kastrup M. Mental health and health-related quality of life: a 10-year follow-up of tortured refugees. J Nerv Ment Dis. 2006 Oct;194(10):725-31.

7. Carlsson JM, Olsen DR, Kastrup M, Mortensen EL. Late mental health changes in tortured refugees in multidisciplinary treatment. J Nerv Ment Dis. 2010 Nov; 198(11):824-8.

8. Palic S, Elklit A. An explorative outcome study of CBT-based multidisciplinary treatment in a diverse group of refugees from a Danish treatment centre for rehabilitation of traumatized refugees. Torture. 2009;19(3):248-70.

9. Palic S, Elklit A. Psychosocial treatment of posttraumatic stress disorder in adult refugees: a systematic review of prospective treatment outcome studies and a critique. J Affect Disord. 2011 Jun;131(1-3):8-23. 10. Nickerson A, Bryant RA, Silove D, Steel Z. A critical review of psychological treatments of posttraumatic stress disorder in refugees. Clin Psychol Rev. 2011 Apr;31(3):399417.

11. Mollica RF, Caspi-Yavin Y, Bollini P, Truong T, Tor S, Lavelle J. The Harvard Trauma Questionnaire. Validating a cross-cultural instrument for measuring torture, trauma, and posttraumatic stress disorder in Indochinese refugees. J Nerv Ment Dis. 1992 Feb;180(2):111-6.

12. Mollica RF, Wyshak G, de Marneffe D, Khuon F, Lavelle J. Indochinese versions of the Hopkins Symptom Checklist-25: a screening instrument for the psychiatric care of refugees. Am J Psychiatry. 1987 Apr;144(4):497-500.

13. Oruc L, Kapetanovic A, Culhane M, Lavelle J,
Miley K, Forstbauer S, et al. Screening for PTSD and depression in Bosnia and Herzegovina: validating the Harvard Trauma Questionnaire and the Hopkins Symptom Cheklist. Int J Culture Ment Health. 2008 Dec;1(2):105-116.

14. Kleijn WC, Hovens JE, Rodenburg JJ. Posttraumatic stress symptoms in refugees: assessments with the Harvard Trauma Questionnaire and the Hopkins symptom Checklist-25 in different languages. Psychol Rep. 2001 Apr;88(2):527-32.

15. WHO. Info package; mastering depression in primary care Frederiksborg, Denmark: World Health Organisation, Regional Office for Europe, Psychiatric Research Unit; 1998 [updated 1998]. Available from: http://www.who-5.org.

16. Sheehan KH, Sheehan DV. Assessing treatment effects in clinical trials with the discan metric of the Sheehan Disability Scale. IntClinPsychopharmacol. 2008 Mar;23(2):70-83.

17. Lam RW, Michalak EE, Swinson RP. Assessment scales in depression, mania and anxiety. London: Taylor \& Francis; 2005. p. 152-3.

18. Cohen J. Statistical power analysis for the behavioural sciences. 2nd ed: Lawrence Erlbaum Associates; 1988.

19. Jacobson NS, Truax P. Clinical significance: a statistical approach to defining meaningful change in psychotherapy research. J Consult Clin Psychol. $1991 \mathrm{Feb} ; 59(1): 12-9$.

20. Buhmann CB, Mortensen EL, Andersen I, Ryberg J, Nordentoft M, Ekstroem M. Cognitive Behavioral Psychotherapeutic treatment at a psychiatric trauma clinic for Refugees: description and evaluation. Torture. 2015;25(1):pp.

21. Basoglu M. Rehabilitation of traumatised refugees and survivors of torture. BMJ. 2006 Dec 16;333(7581):1230-1.

22. Jakobsen M, Thoresen S, Johansen,L.E.E. The validity of screening for post-traumatic stress disorder and other mental health problems among asylum seekers from different countries. Journal of Refugee Studies. 2011;24(1):171-86.

23. Buhmann C, Mortensen EL, Lundstroem S, Ryberg J, Nordentoft M, Ekstroem M. Symptoms, Quality of Life and level of functioning of traumatized refugees at Psychiatric Trauma Clinic in Copenhagen. Torture. 2014;24 (1): 25-39.

24. Sheehan DV, Kamijima K. An evidence-based review of the clinical use of sertraline in mood and anxiety disorders. Int Clin Psychopharmacol. 2009 Mar;24(2):43-60.

25. Mayers AG, Baldwin DS. Antidepressants and their effect on sleep. Hum Psychopharmacol. 2005 Dec;20(8):533-59.

26. Marshall GN, Schell TL, Elliott MN, Berthold 
SM, Chun CA. Mental health of Cambodian refugees 2 decades after resettlement in the United States. JAMA. 2005 Aug;294(5):571-9.

27. Lie B. A 3-year follow-up study of psychosocial functioning and general symptoms in settled refugees. Acta Psychiatr Scand. 2002 Dec;106(6):415-25.

28. Blair RG. Risk factors associated with PTSD and major depression among Cambodian refugees in Utah. Health Soc Work. 2000 Feb;25(1):23-30.

29. Beiser M, Hou F. Language acquisition, unemployment and depressive disorder among Southeast Asian refugees: a 10-year study. Soc Sci Med. 2001 Nov;53(10):1321-34.

30. Bhui K, Craig T, Mohamud S, Warfa N, Stansfeld SA, Thornicroft G, et al. Mental disorders among Somali refugees: developing culturally appropriate measures and assessing socio-cultural risk factors. Soc Psychiatry Psychiatr Epidemiol. 2006 May;41(5):400-8.

31. Lindencrona F, Ekblad S, Hauff E. Mental health of recently resettled refugees from the Middle East in Sweden: the impact of pre-resettlement trauma, resettlement stress and capacity to handle stress. Soc Psychiatry Psychiatr Epidemiol. 2008 Feb;43(2):121-31.

32. Carlsson JM, Mortensen EL, Kastrup M. Predictors of mental health and quality of life in male tortured refugees. Nord J Psychiatry. 2006;60(1):51-7.

33. Gorst-Unsworth C, Goldenberg E. Psychological sequelae of torture and organised violence suffered by refugees from Iraq. Trauma-related factors compared with social factors in exile. $\mathrm{Br} \mathrm{J}$ Psychiatry. 1998 Jan;172:90-4.

34. Hermansson AC, Timpka T, Thyberg M. The mental health of war-wounded refugees: an 8-year follow-up. J Nerv MentDis. 2002 Jun;190(6):374-80.

35. Asmundson GJ, Coons MJ, Taylor S, Katz J. PTSD and the experience of pain: research and clinical implications of shared vulnerability and mutual maintenance models. Can J Psychiatry. 2002 Dec;47(10):930-7.

36. Asmundson GJ, Katz J. Understanding the co-occurrence of anxiety disorders and chronic pain: state-of-the-art. Depress Anxiety. 2009;26(10):888-901.

37. Poundja J, Fikretoglu D, Brunet A. The co-occurrence of posttraumatic stress disorder symptoms and pain: is depression a mediator? J Trauma Stress. 2006 Oct;19(5):747-51.

38. Moskowitz A. Schizophrenia, trauma, dissociation, and scientific revolutions. J Trauma Dissociation. 2011;12(4):347-57.
39. Neuner F, Kurreck S, Ruf M, Odenwald M, Elbert T, Schauer M. Can asylum-seekers with posttraumatic stress disorder be successfully treated? A randomized controlled pilot study. Cogn Behav Ther. 2010;39(2):81-91.

40. Neuner F, Onyut PL, Ertl V, Odenwald M, Schauer E, Elbert T. Treatment of posttraumatic stress disorder by trained lay counselors in an African refugee settlement: a randomized controlled trial. J Consult Clin Psychol. 2008 Aug;76(4):686-94.

41. Neuner F, Schauer M, Klaschik C, Karunakara U, Elbert T. A comparison of narrative exposure therapy, supportive counseling, and psychoeducation for treating posttraumatic stress disorder in an african refugee settlement. JConsult ClinPsychol. 2004;72(4):579-87.

42. Hinton DE, Chhean D, Pich V, Safren SA, Hofmann SG, Pollack MH. A randomized controlled trial of cognitive-behavior therapy for Cambodian refugees with treatment-resistant PTSD and panic attacks: a cross-over design. J Trauma Stress. 2005 Dec;18(6):617-29.

43. Hinton DE, Pham T, Tran M, Safren SA, Otto MW, Pollack MH. CBT for Vietnamese refugees with treatment-resistant PTSD and panic attacks: a pilot study. J Trauma Stress. 2004 Oct;17(5):429-33.

44. Otto MW, Hinton D, Korbly NB, Chea A, Ba $\mathrm{P}$, Gershuny BS, et al. Treatment of pharmacotherapy-refractory posttraumatic stress disorder among Cambodian refugees: a pilot study of combination treatment with cognitive-behavior therapy vs sertraline alone. Behav Res Ther. 2003 Nov;41(11):1271-6.

45. Paunovic N, Ost LG. Cognitive-behavior therapy vs exposure therapy in the treatment of PTSD in refugees. Behav Res Ther. 2001 Oct;39(10):1183-97. 